\title{
Assessing the onset of calcium phosphate nucleation by hyperpolarized real-time NMR
}

Emmanuelle M. M. Weber ${ }^{[a]}$, Thomas Kress ${ }^{[b]}$, Daniel Abergel ${ }^{[c]}$, Steffi Sewsurn ${ }^{[d]}$, Thierry Azaïs ${ }^{[d]}{ }^{*}$, Dennis Kurzbach ${ }^{[b], *}$

[a] Radiological Sciences Laboratory, Department of Radiology, Stan-ford University, Richard M. Lucas Center for Imaging, 201 Welch Rd, Stanford, CA 94305, United States

[b] University Vienna, Faculty of Chemistry, Institute of Biological Chemistry, Währinger Str. 38, 1090 Vienna, Austria E-mail: dennis.kurzbach@univie.ac.at

[c] Laboratoire des Biomolécules, LBM, Département de chimie, École Normale Supérieure, PSL University, Sorbonne Université, CNRS, 24 rue Lhomond, 75005 Paris, France

[d] Sorbonne Université, CNRS, Collège de France, Laboratoire de Chimie de la Matière Condensée de Paris (LCMCP), 4, place Jussieu, F-75005, Paris France

E-mail: thierry.azais@upmc.fr

\section{Supporting Information}

\section{Table of Contents}

D-DNP reference experiments

Fitting Results
Page S2

Page S4 


\section{D-DNP reference experiments}

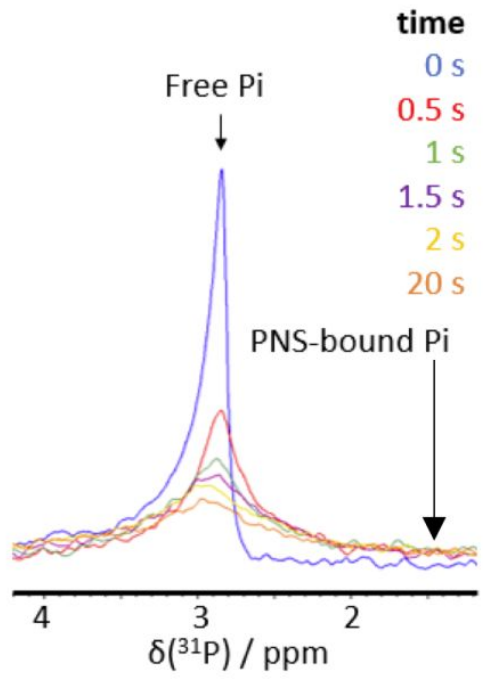

Figure S1. ${ }^{31} \mathrm{P}$ spectra detected after injection of a $13 \mathrm{mM} \mathrm{CaCl} 2$ solution into a $\mathrm{P}_{\mathrm{i}}$ solution without D-DNP. The mixing process was completed at $t=0$ when NMR detection with a $2 \mathrm{~Hz}$ sampling rate was initiated. Without hyperpolarization, no significant trace of PNS-bound $P_{i}$ could be detected (expected frequency indicated by an arrow). The signal of free $\mathrm{Pi}$ is decreasing due to $\mathrm{CaP}$ precipitation. All spectra were phase-corrected identically. The shape of the blue line is distorted due to turbulences during the mixing process. 
a)

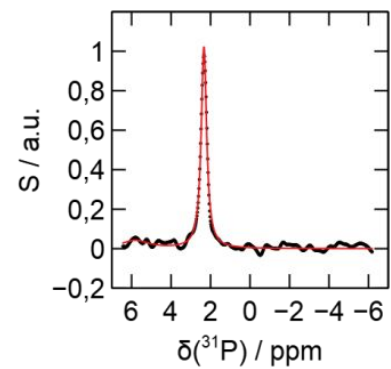

b)

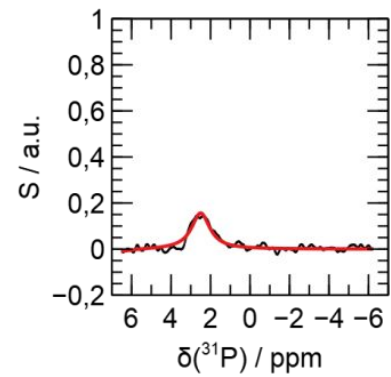

c)

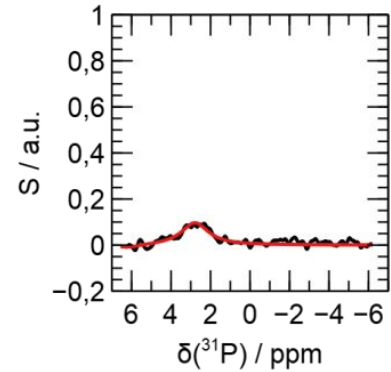

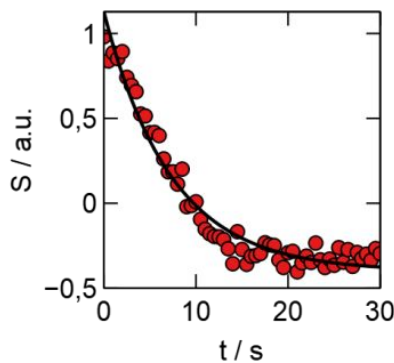
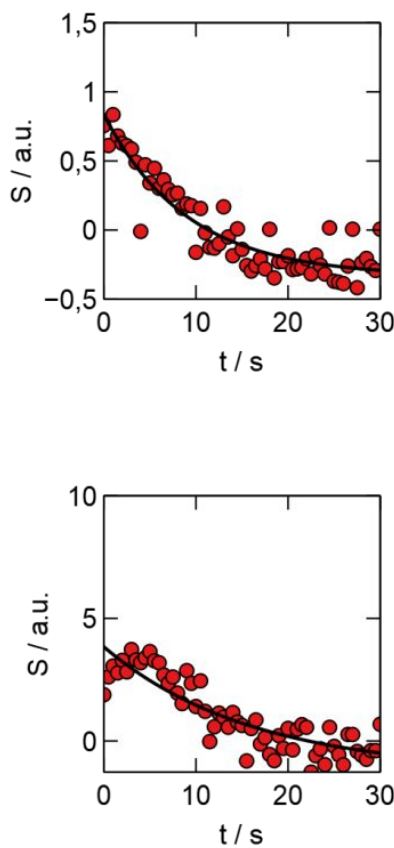

Figure S2. D-DNP ${ }^{31} \mathrm{P}$ NMR spectrum of various $\mathrm{Pi}$ and $\mathrm{Ca}^{2+}$ solutions (recorded at $2 \mathrm{~s}$ after mixing) and time dependence of the ${ }^{31} \mathrm{P}$ signal intensity. At elevated concentrations, the PNS aggregation proceeds too fast for realtime monitoring by solution-state NMR. a) Data for injection of $\mathrm{P}_{\mathrm{i}}$ into a $25 \mathrm{mM} \mathrm{CaCl}_{2}$ solution. The CaP precipitation is so fast that PNS signal is not observed after the mixing process. Instead only free $\mathrm{P}_{\mathrm{i}}$ remains in solution for which monotone signal decay is observed. b) Same as in (a), but at a concentration of $\left[\mathrm{Ca}^{2+}\right]=50 \mathrm{mM}$. The ${ }^{31} \mathrm{P}$ signal is weaker due to facilitated aggregation and precipitation of $\mathrm{CaP}$ at higher concentration (cf. turbidimetry results of the main text). The signal decay remains clearly monoexponential. However, line shape analysis become unreliable due to the low SNR. c) Same as in (b) but at $\left[\mathrm{Ca}^{2+}\right]=100 \mathrm{mM}$. The signal-to-noise ratio drops further and now even the signal decay becomes difficult to analyze. 
Fitting results
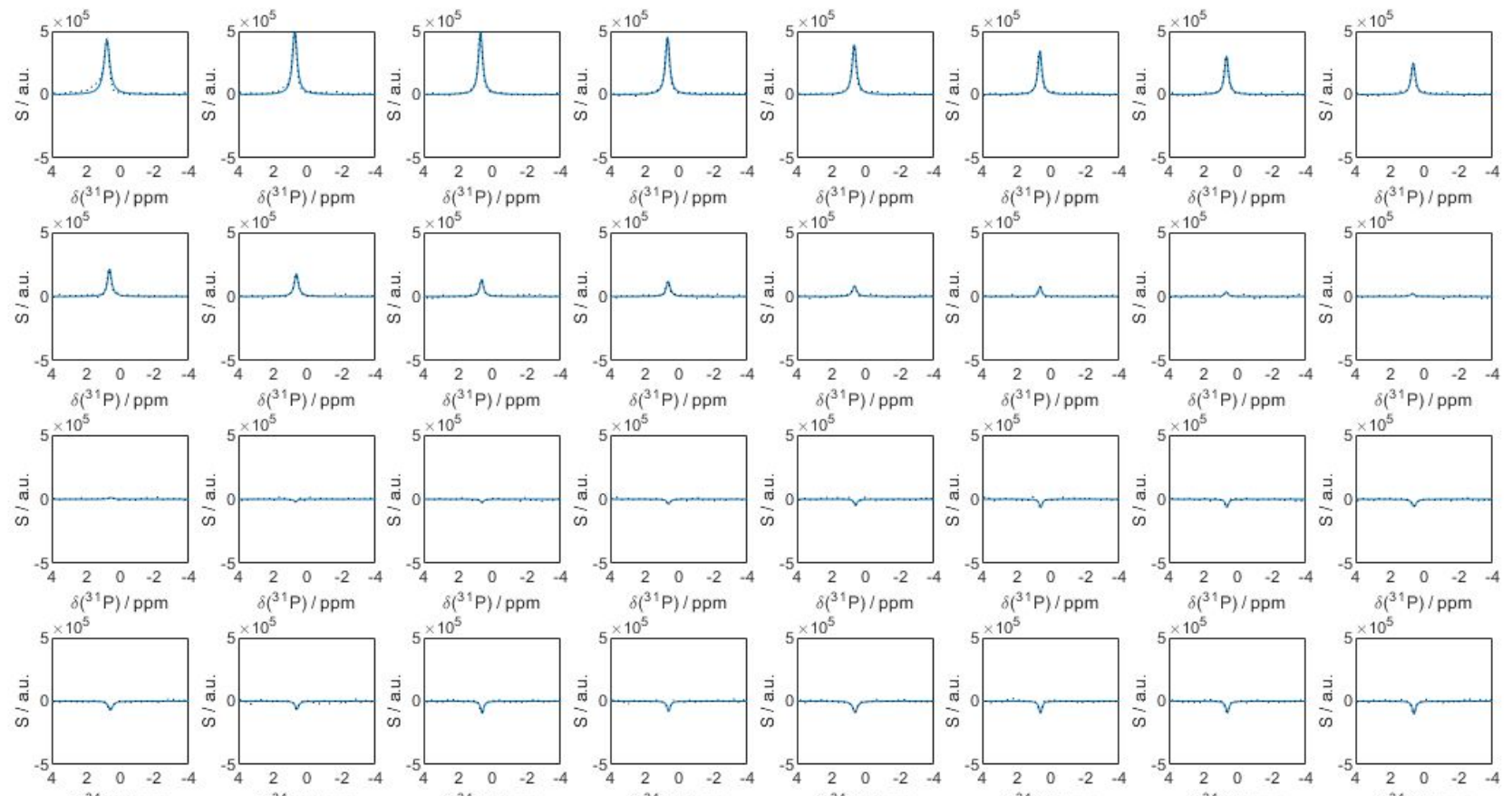

$\delta\left(\left(^{31} \mathrm{P}\right) / \mathrm{ppm}\right.$

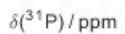

$\delta\left({ }^{31} \mathrm{P}\right) / \mathrm{ppm}$
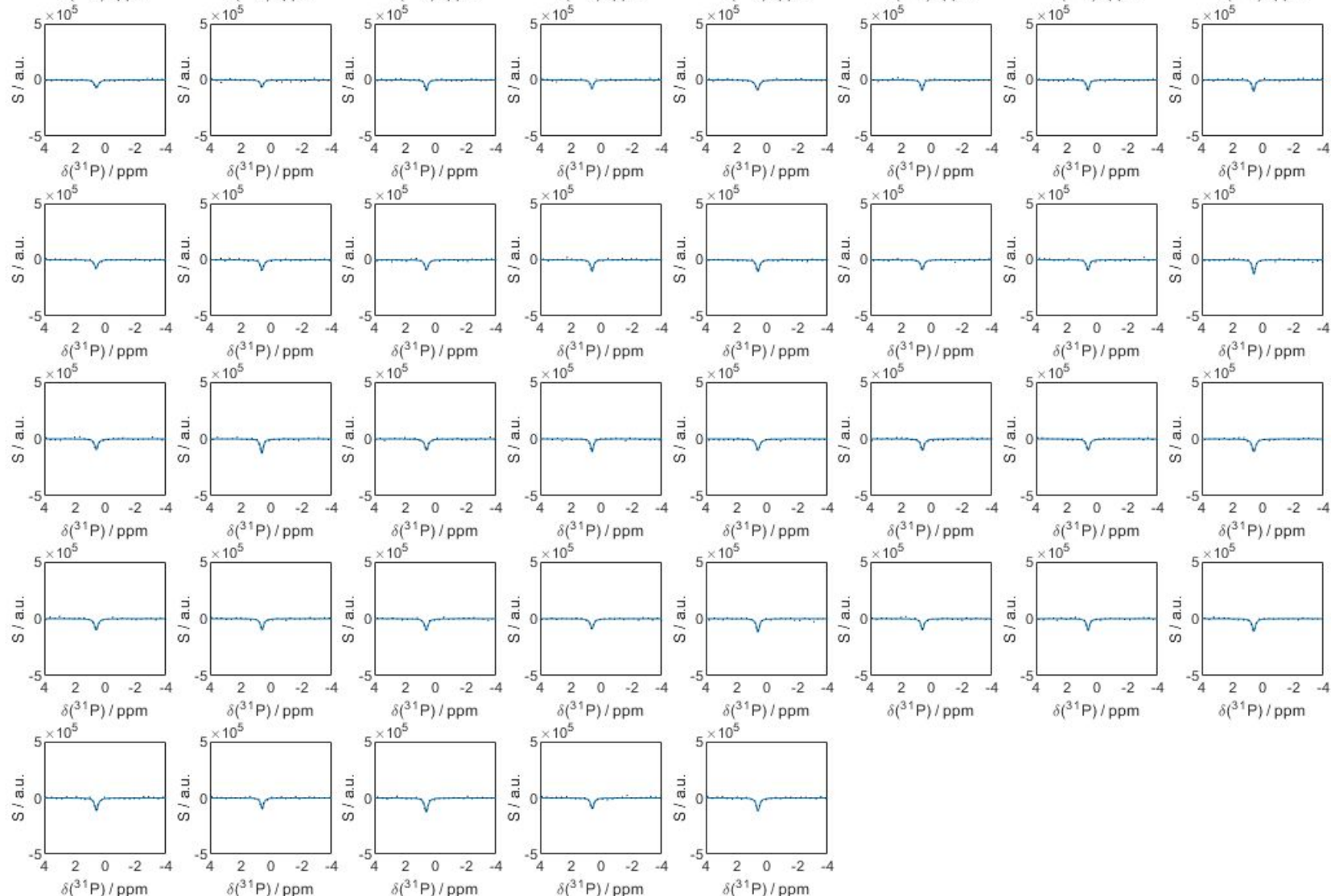

$\delta\left({ }^{31} \mathrm{P}\right) / \mathrm{ppm}$

$\delta\left({ }^{31} \mathrm{P}\right) / \mathrm{ppm}$

Figure S3. Spectra (black dots) and monomodal fits (blue lines) of $P_{i}$ after dissolution and mixing with neat buffer (reference experiment with $\left[\mathrm{Ca}^{2+}=0\right]$ ). The delay between each detection was $0.5 \mathrm{~s}$. Note that he linewidth is constant throughout the experiment showing that biases due to shim instabilities or turbulences are negligible. Negative DNP was used. The signal amplitude therefore switches sign. 

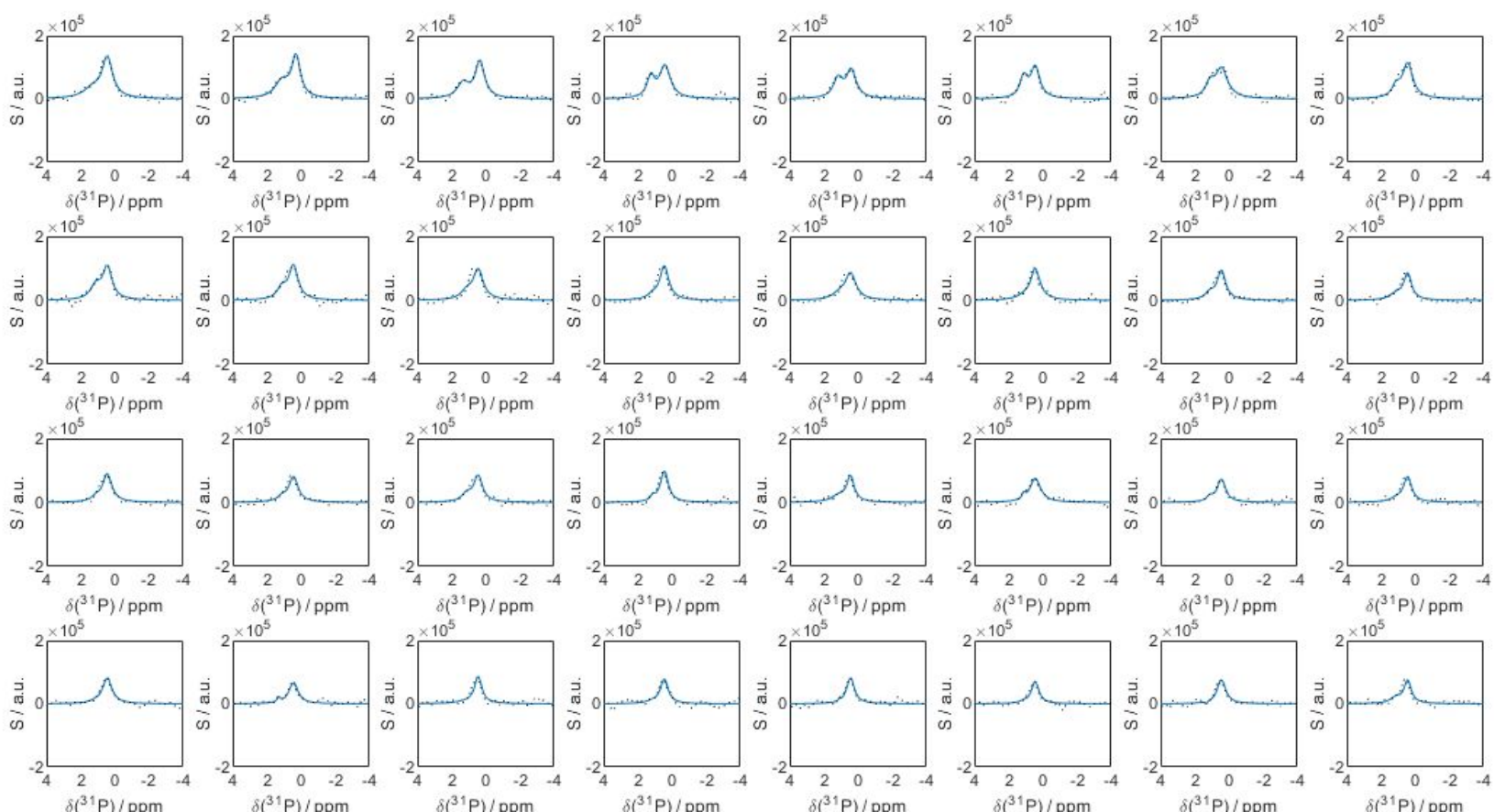

$\delta\left({ }^{31} \mathrm{P}\right) / \mathrm{ppm}$

$\delta\left({ }^{31} \mathrm{P}\right) / \mathrm{ppm}$
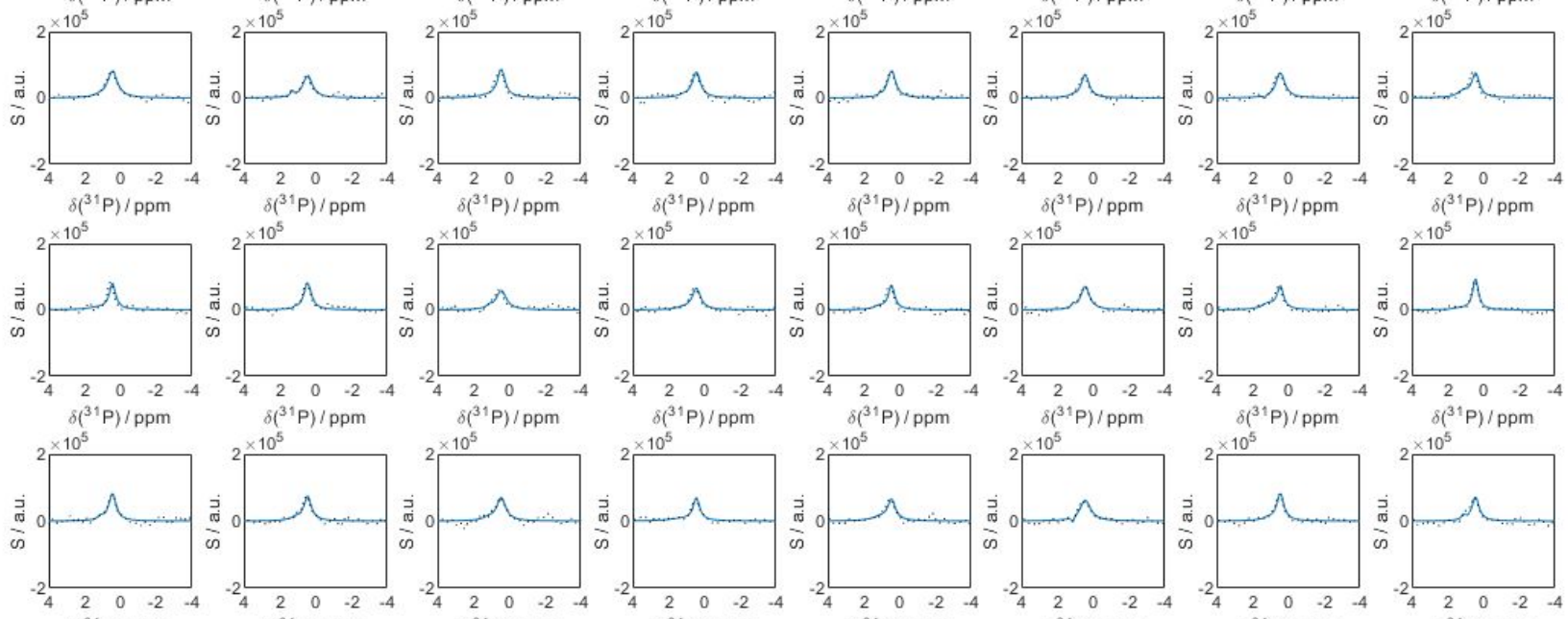

$\delta\left({ }^{31} \mathrm{P}\right) / \mathrm{ppm}$
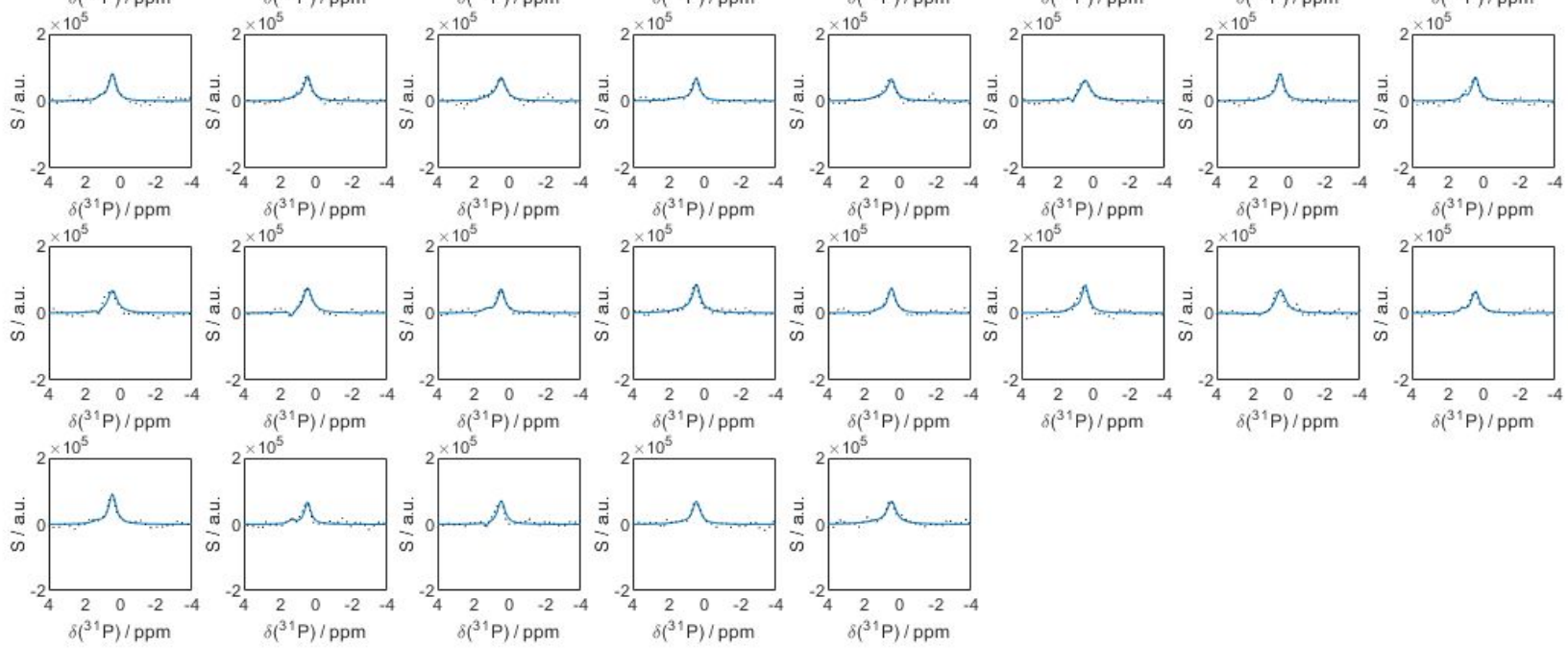

Figure S4. Spectra (black dots) and bimodal fits (blue lines) of $\mathrm{P}_{\mathrm{i}}$ after dissolution and mixing with an $8 \mathrm{mM} \mathrm{CaCl}$ buffered solution. The delay between each detection was $0.5 \mathrm{~s}$. Positive DNP was used. Note that the signal amplitude does not pass through 0 as in Fig. S3 due to the opposite sign of the hyperpolarization in this experiment (here positive, but negative in Fig. S3). 

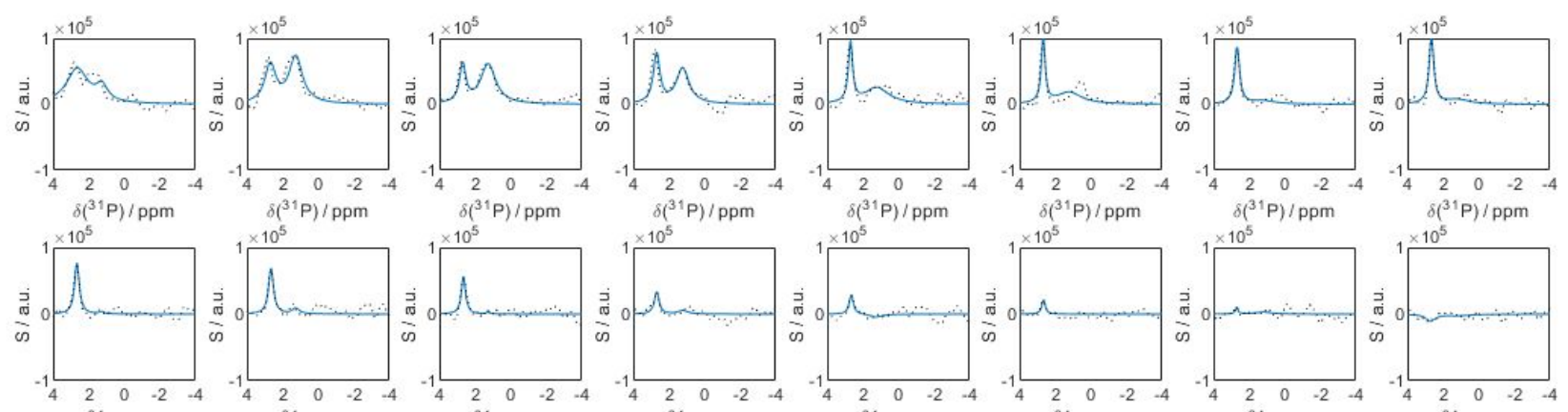

$\delta\left({ }^{31} \mathrm{P}\right) / \mathrm{ppm}$
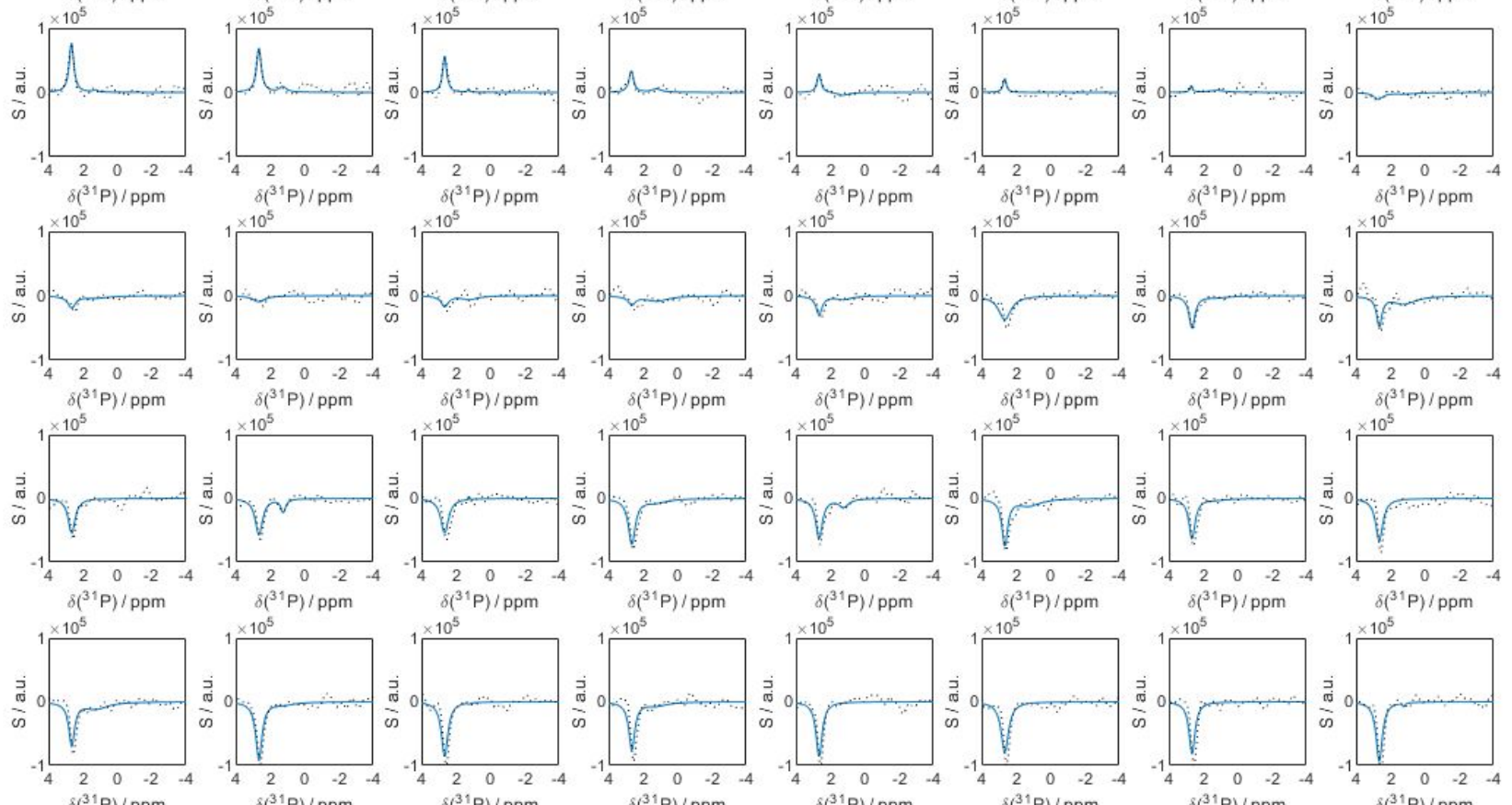

$\delta\left({ }^{31} \mathrm{P}\right) / \mathrm{ppm}$

$\delta\left({ }^{31} \mathrm{P}\right) / \mathrm{ppm}$
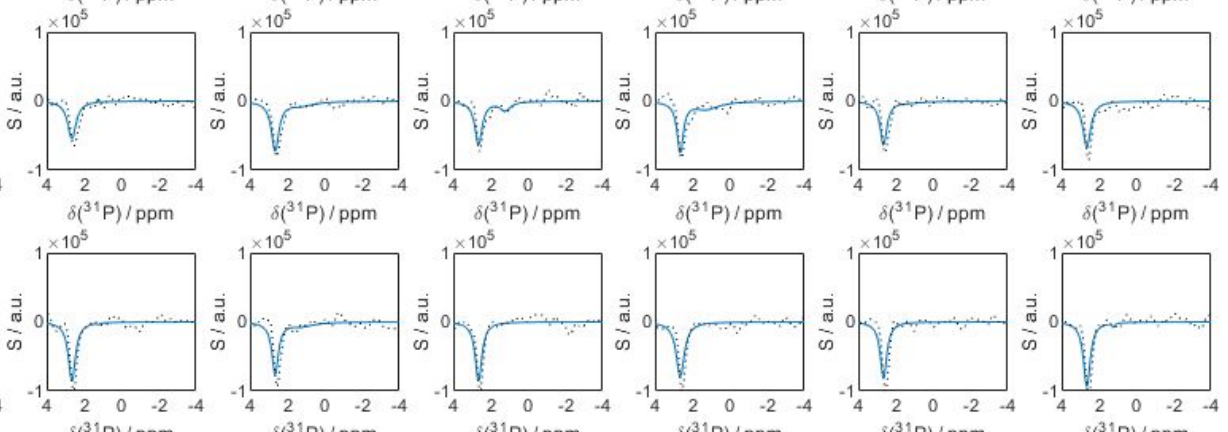

$\delta\left({ }^{31} \mathrm{P}\right) / \mathrm{ppm}$

$\delta\left({ }^{31} \mathrm{P}\right) / \mathrm{ppm}$

$\delta\left({ }^{31} \mathrm{P}\right) / \mathrm{ppm}$
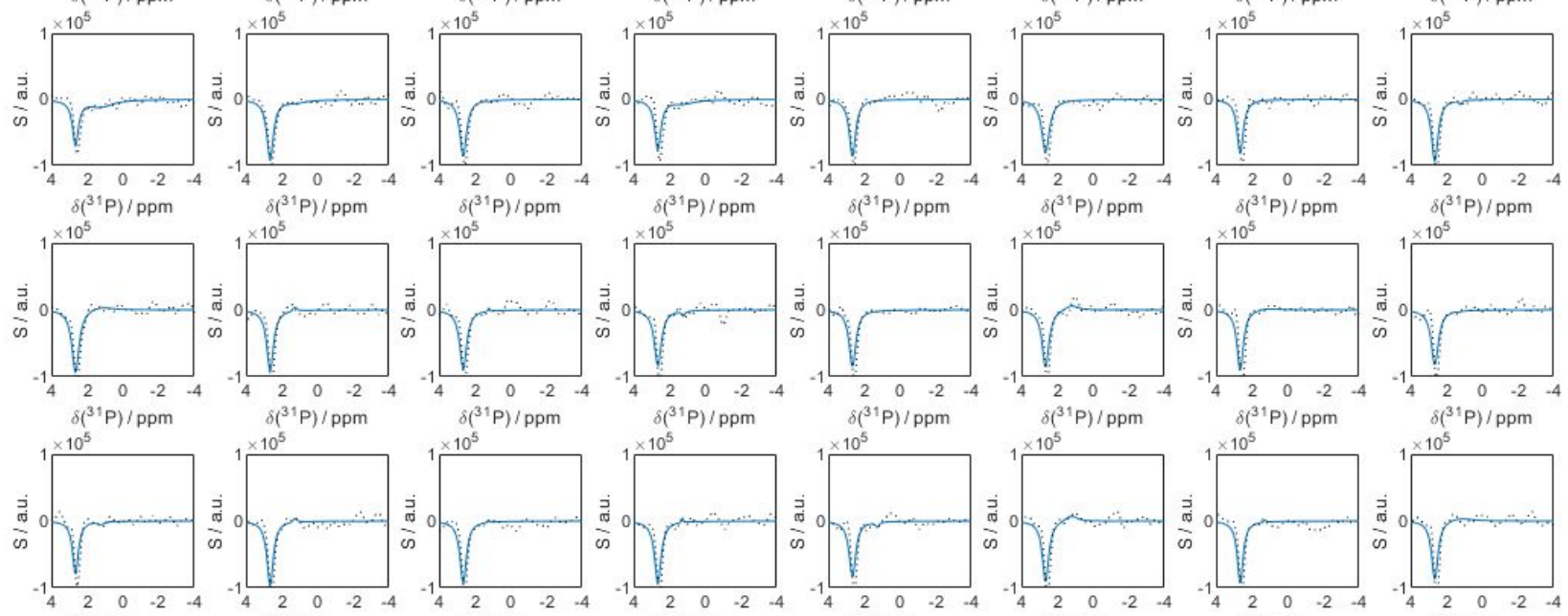

$\delta\left({ }^{31} \mathrm{P}\right) / \mathrm{ppm}$
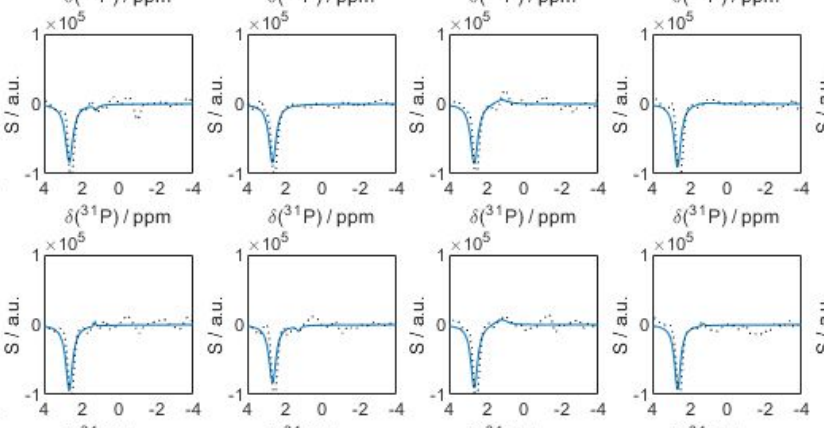

$\delta\left({ }^{31} \mathrm{P}\right) / \mathrm{ppm}$
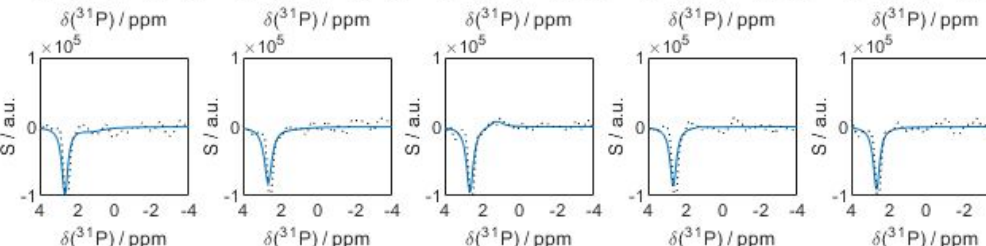

$\delta\left({ }^{31} \mathrm{P}\right) / \mathrm{ppm}$

$\delta\left({ }^{31} \mathrm{P}\right) / \mathrm{ppm}$
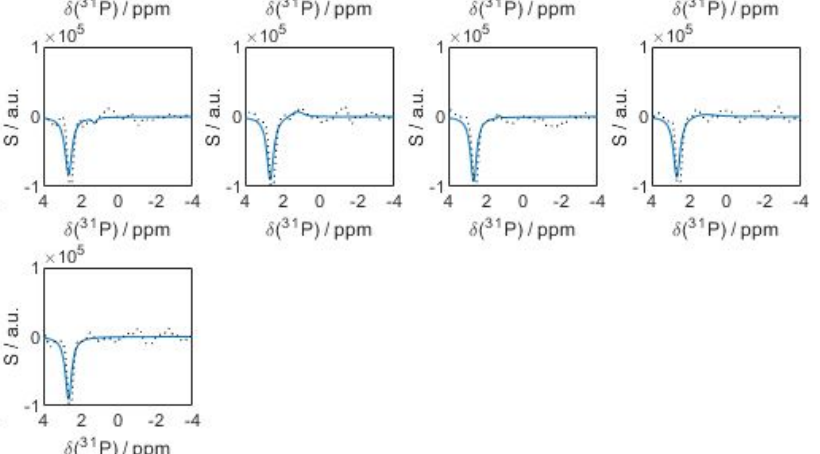

$\delta\left({ }^{31} \mathrm{P}\right) / \mathrm{ppm}$

Figure S5. Spectra (black dots) and bimodal fits (blue lines) of $\mathrm{P}_{\mathrm{i}}$ after dissolution and mixing with a $13 \mathrm{mM} \mathrm{CaCl}$ buffered solution. The delay between each detection was $0.5 \mathrm{~s}$. Negative DNP was used. The signal amplitude therefore switches sign. 